\title{
Simulação da movimentação de pessoas em situações de emergência: aspectos ergonômicos e computacionais com autômatos Fuzzy e sua aplicação ao projeto arquitetônico
}

\author{
Simulation of the movement of people in emergency \\ situations: ergonomic and computational aspects with \\ fuzzy automata and its application in architectural design
}

Henrique Costa Braga
Centro Federal de Educação
Tecnológica
Belo Horizonte - MG - Brasil

Gray Farias Moita Centro Federal de Educação Tecnológica Belo Horizonte - MG - Brasil

Fausto Camargo Centro Federal de Educação Tecnológica
- MG - Brasil Belo Horizonte - MG - Brasil

Paulo Eduardo Maciel de Almeida Centro Federal de Educação Tecnológica Belo Horizonte - MG - Brasil

Recebido em 21/02/14 Aceito em 11/04/14

\section{Henrique Costa Braga \\ Gray Farias Moita \\ Fausto Camargo \\ Paulo Eduardo Maciel de Almeida}

\section{Resumo}

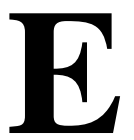

ste artigo apresenta o programa computacional Fuga, desenvolvido para simular a movimentação de pessoas em ambientes construídos durante uma situação de abandono. Esse programa se baseia na modelagem celular e possui como principais paradigmas a utilização de aspectos ergonômicos associados à movimentação humana e a utilização da Lógica Fuzzy como ferramenta de inteligência computacional para emulação do processo de tomada de decisão humana. Os aspectos ergonômicos e o processo de tomada de decisões são apresentados. É realizada uma validação do modelo, assim como várias simulações, ilustrando como pode ser utilizado na concepção de ambientes mais seguros, de uma forma que dificilmente seria obtida pela simples aplicação das legislações vigentes.

Palavras-chave: Simulação. Ergonomia. Lógica Fuzzy. Movimentação de pessoas.

\section{Abstract}
This paper presents the computer program FUGA, developed to simulate the movement of people in built environments during an evacuation. This program is based on cellular modelling and its main paradigms are the use of ergonomic aspects associated with human movement and the use of Fuzzy Logic as a computer intelligence tool to emulate the human decision-making process. The ergonomic aspects and the decision-making process are presented. A validation of the model was undertaken, as well as several simulations, illustrating how the software can be used in the design of safer environments in a way that could hardly be achieved through by applying the existing regulations.
Keywords: Simulation. Ergonomics. Fuzzy Logic. Movement of people. 


\section{Introdução}

Aconteceu em 2013, na cidade de Santa Maria, RS, Brasil, uma grande tragédia em uma casa noturna, tendo havido mais de 240 fatalidades (SILVA FILHO, 2013). Esta foi oficialmente a segunda maior tragédia dessa natureza ocorrida na história do país (a maior dos últimos 50 anos), sendo somente superada pelo incêndio do Gran Circus Norte-Americano de Niterói, RJ, em 1961 (KNAUSS, 2007). Como normalmente ocorre em tragédias dessa magnitude e espécie, são muitos os fatores corresponsáveis pelo sinistro e a dimensão alcançada, sendo também um terrível exemplo de como ainda há muito para se fazer na área de planejamento de ambientes, incluindo $o$ aprimoramento da normalização.

Adicionalmente, apesar de as normas e leis prescritivas que regulamentam os detalhes globais para a realização dos projetos dos ambientes serem de fundamental importância, elas são generalistas e podem não ser capazes de prever ou evitar condições não ideais ou mesmo situações perigosas. Dessa forma, a existência de um programa computacional confiável que auxilie na verificação das condições de fluidez e segurança de um ambiente se torna de relevante valor, como um complemento à aplicação das normas, leis e conhecimentos já estabelecidos. Projetos baseados em desempenho (CLARET; MATTEDI, 2011), a aplicação de parâmetros de qualidade (ONO, 2007), de índices de segurança como o de Gretener (SILVA; COELHO FILHO, 2007), ou a realização da otimização de ambientes (TAVARES; GALEA, 2009) podem se beneficiar desse tipo de programa.

Assim, este trabalho tem como objetivo apresentar uma modelagem da movimentação humana baseada em paradigmas ainda pouco trabalhados para tal, a ergonomia e a Lógica Fuzzy. Esse modelo foi efetivamente implementado na forma de um programa computacional denominado Fuga, que possibilita realizar estudos sobre a segurança e fluidez de ambientes, contribuindo na valoração da segurança de ambientes e no projeto arquitetônico.

\section{Fundamentação teórica}

Pela importância, já existem diversos estudos e programas computacionais desenvolvidos para realizar a simulação da movimentação humana em ambientes construídos (HELBING; FARKAS; VICSEK, 2000; PELECHANO; ALLBECK; BADLER, 2008; KOBES et al., 2010; KULIGOWSKI, 2013). Cada um dos modelos se utiliza de algum princípio diferente, de forma a ser, na concepção de seus criadores, o mais realístico ou adequado a uma situação específica. Entretanto, existem dois paradigmas que ainda não foram suficientemente abordados nas modelagens já concebidas: a ergonomia e a Lógica Fuzzy. Esses paradigmas podem propiciar a realização de modelos mais realísticos e ser uma contribuição ao conhecimento já estabelecido.

As nuanças envolvidas no processo de movimentação humana são multidisciplinares, envolvendo os mais diversos aspectos, tais como físicos, ambientais, biológicos, organizacionais e mentais. Esses parâmetros possuem sinergia entre si, são individuais e específicos, ao mesmo tempo que coletivos, dinâmicos e muitas vezes emergentes (GOLDSTONE; ROBERTS, 2006). Comparando essas subdivisões com as áreas e segmentações da ergonomia (IIDA, 2010), percebe-se grande semelhança. Um sistema ergonômico complexo (VIDAL; BONFATTI; CARVÃO, 2002) inclui o processo de movimentação humana.

Assim, o design arquitetônico de um ambiente construído deve considerar os aspectos ergonômicos envolvidos, de forma a melhor se adaptar às necessidades, características e realidade das pessoas que o vão utilizar. Na Figura 1 se apresenta uma representação de alguns dos diversos aspectos envolvidos na movimentação de pessoas. Apesar de abrangente, tal relação não é de forma alguma completa.

Para que uma modelagem seja realizada, é necessária a seleção das variáveis consideradas prioritárias no contexto específico a ser estudado. Essas variáveis devem, então, por meio de regras ou algoritmos computacionais, ser relacionadas dinamicamente entre si.

Um ponto crítico está no processo de tomada de decisões. $\mathrm{O}$ processo real de cognição e consciência, que ocasiona uma tomada de decisão humana e uma correspondente ação, é extremamente complexo (CARTER, 2003; EDELMAN, 1992; VIDAL; CARVALHO, 2008). Assim sendo, como então modelar completamente esse sistema para se determinar a rota que seria escolhida por uma pessoa em um contexto de emergência? Utilizando-se do Princípio da Incompatibilidade de Zadeh ${ }^{1}$ (SIMÕES; SHAW, 2007), tem-se uma resposta natural e extremamente simples: não há como, e talvez nunca haja!

\footnotetext{
1“Com o aumento da complexidade de um sistema, a nossa habilidade de fazer afirmações precisas e ainda significantes a respeito do seu comportamento diminui até um limiar ser alcançado, a partir do qual a PRECISÃO e a SIGNIFICÂNCIA (ou relevância) tornam-se características mutuamente exclusivas.".
} 
Figura 1 - Diversas facetas envolvidas na movimentação de pessoas

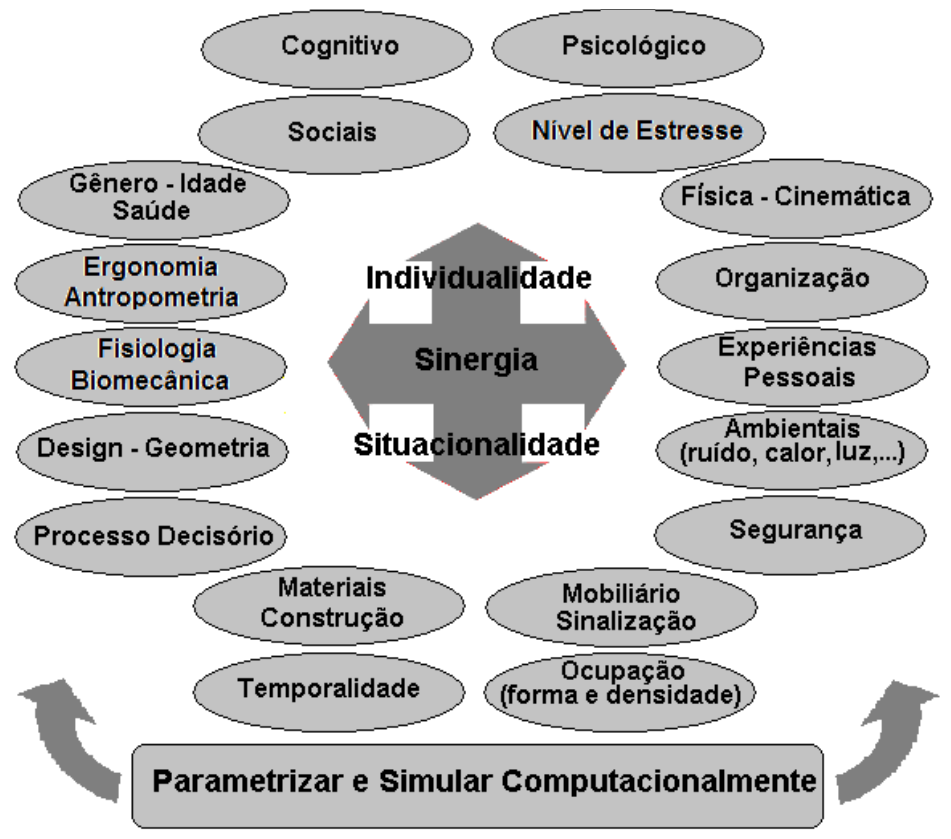

Uma alternativa, que a princípio pode parecer - e na verdade o é - extremamente simplista, está na adoção de alguma ferramenta de Inteligência Computacional (IC) para emular a tomada de decisão humana. Entre as ferramentas de IC disponíveis, o emprego da Lógica Fuzzy se destaca por sua capacidade de incorporar diversas variáveis qualitativas e quantitativas em um processo decisório, pela possibilidade de contextualizar numericamente um dito conhecimento especialista (ALMEIDA; EVSUKOFF, 2003), além de possuir correlatos biológicos (ROJAS, 1996).

A Lógica Fuzzy nada mais é que uma ferramenta determinística de gerenciamento de incertezas, que podem ser oriundas de grandezas mensuráveis ou puramente qualitativas. Assim, a Lógica Fuzzy aparece como sendo promissora para pesquisas e modelagem de tomadas de decisão humanas envolvendo aspectos ergonômicos (NUNES, 2010), mesmo quando baseada em parâmetros qualitativos ou mentais.

Por se viver em uma sociedade cultural e historicamente representacionista, centrada na ação, e não na reflexão, sempre que possível há uma preferência de se utilizarem parâmetros quantitativos ao invés de qualitativos. Entretanto, a subjetividade (tanto quanto a objetividade) e a qualidade (tanto quanto a quantidade) são na verdade indispensáveis ao conhecimento e, portanto, à ciência (MATURANA; VARELA, 2010). Neste modelo, por sua natureza, é indispensável que se trabalhe com tomadas de decisões considerando a ocorrência de variáveis subjetivas e qualitativas, o que é facilitado pela Lógica Fuzzy.

\section{Desenvolvimento}

\section{Discretização do ambiente construído}

Um ambiente construído pode ser representado na forma de uma matriz (PEREIRA, 2007). Assim, o primeiro passo na simulação é realizar a discretização do ambiente construído a ser simulado para a forma de uma matriz retangular, que é denominada de matriz ambiente geral. O ambiente construído a ser simulado pode ter qualquer formato, mas deve ser simplificado, de forma que todos os seus elementos fiquem como múltiplos de quadrados de um valor $r$, denominado de resolução da simulação. Assim, cada elemento da matriz ambiente geral corresponde a $r$, que é o maior deslocamento possível em uma única iteração, assim como a precisão requerida para todos os elementos do ambiente. Nesta versão do programa Fuga, os ambientes devem ter um único nível ou andar. A resolução da simulação $r$ é fixada como $9 \mathrm{~cm}$ (este valor para $r$ foi estabelecido empiricamente para essa versão do programa Fuga como sendo o mais apropriado, considerando um balanço entre custo computacional e precisão).

Cada elemento da matriz ambiente geral possuirá um número com um significado. Assim, a montagem do ambiente construído discreto significa a criação de uma matriz retangular o 
representando, com todos os seus elementos valendo: "9", caracterizando os espaços vazios no ambiente; "0", caracterizando os obstáculos ou restrições; ou "6", caracterizando as saídas do ambiente. Não é possível alterar essa matriz ambiente construído inicial durante a simulação. As pessoas serão caracterizadas pelo número " 1 " e, obviamente, se moverão durante a simulação. $\mathrm{Na}$ Figura 2, é apresentado um exemplo da discretização de um ambiente construído e a respectiva matriz ambiente geral obtida.

Quando uma pessoa se move no ambiente construído significa que há uma troca dos valores na matriz ambiente geral que passarão a ser ocupados pela pessoa, de "9" (espaço vazio) para "1" (espaço ocupado por uma pessoa), assim como o correspondente espaço que esta pessoa desocupou na matriz resulta numa mudança de " 1 " para "9" no correspondente valor deste elemento na matriz ambiente geral. Na matriz (ou ambiente) são permitidos diretamente apenas movimentos conforme a vizinhança de Von Neumann, ou seja, poderão ocorrer movimentos de um elemento de matriz para os elementos acima (U), abaixo (D), à direita (R) ou à esquerda (L), considerando sempre uma vista de topo do ambiente. Não são permitidos movimentos diretos nas diagonais da matriz. Não é permitida a superposição de pessoas por outras pessoas ou obstáculos. Na Figura 3 se tem uma representação esquemática de parte de uma matriz ambiente geral com a indicação das possíveis possibilidades de deslocamento direto, em que a posição atual é o elemento de matriz relativo à posição central da pessoa.

\section{Aspectos antropométricos}

Pessoas são como objetos tridimensionais, e uma completa descrição de sua altamente desenvolvida sequência de movimentos não é trivial (VIEL, 2001). Entretanto, conforme considerado por diversos pesquisadores, o atual modelo é baseado em duas dimensões, consistindo simplesmente na projeção vertical do corpo.

Figura 2 - Exemplo em (a) da discretização de um ambiente (sem escala), e em (b) da respectiva matriz ambiente geral obtida

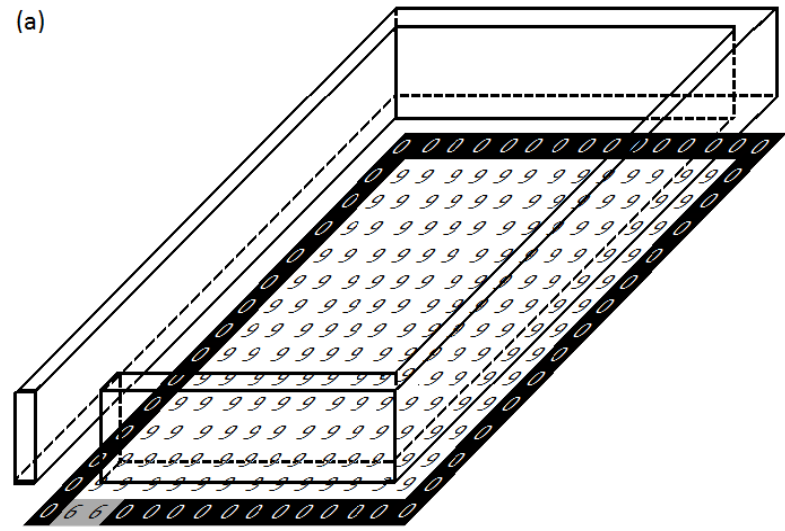

(b)

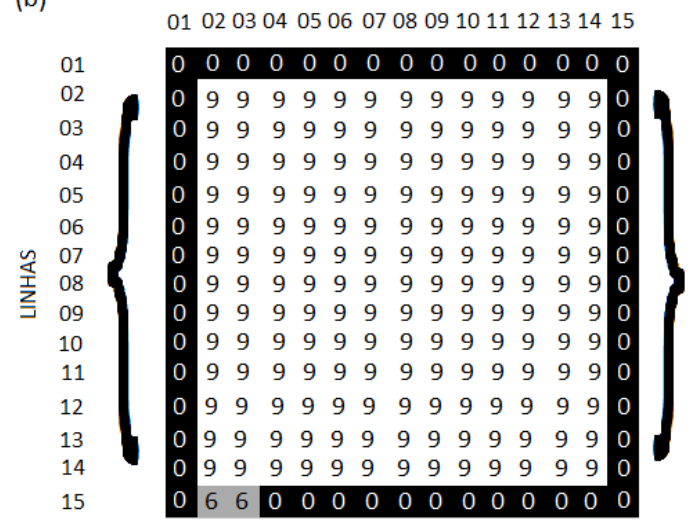

Figura 3 - Representação esquemática de parte de uma matriz ambiente geral com a indicação das possíveis alterações diretas no posicionamento das pessoas

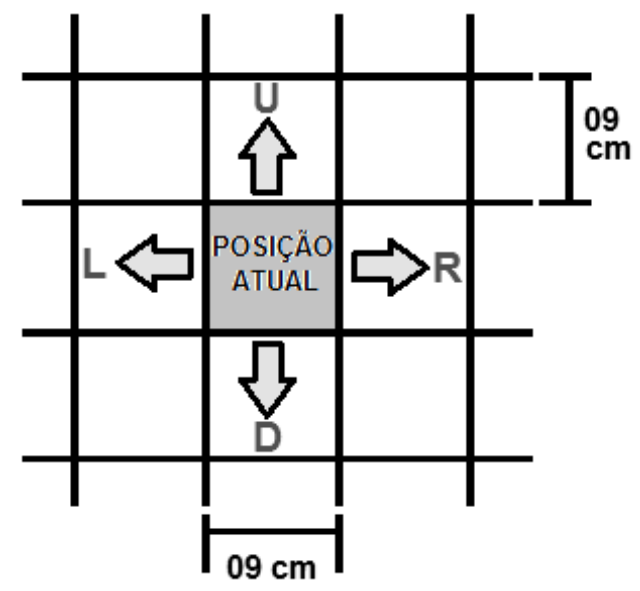

64 Braga, H. C.; Moita, G. F.; Camargo, F.; Almeida, P. E. M. de; 
Segundo Cucci Neto (1996), pesquisas feitas nos Estados Unidos consideram que o corpo visto por cima pode se resumir a uma elipse de $60,9 \mathrm{~cm}$ (comprimento do corpo) por $45,7 \mathrm{~cm}$ (largura do corpo) tendo uma área média de $0,28 \mathrm{~m}^{2}$. Esses valores são propositalmente tendenciosos para cima (são maiores que a média real obtida em estudos de dimensões humanas), de forma a se proteger ou compensar um pouco das grandes variações desses valores. Já outros autores consideram valores inferiores, como Still (2000), que aproxima o corpo humano a uma elipse de 58 $\mathrm{cm}$ por $33 \mathrm{~cm}$. A National Institute of Standards and Technology (NIST), por outro lado, considera em seus modelos uma geometria distinta (não elíptica) constituída por três círculos, formando o torso e os ombros (KULIGOWSKI; PEACOCK, 2005). Outros autores (HELBING; FARKAS; VICSEK, 2000; PEREIRA, 2007) consideraram o corpo visto por cima como uma simples circunferência ou quadrado. Na verdade, não existe um perfil único, já que se tem enorme variabilidade entre países, etnias, idade, gênero, e mesmo entre indivíduos (a muito discutida falácia do homem médio). Um valor considerado por alguns autores como satisfatoriamente médio é o de $0,20 \mathrm{~m}^{2}$ de área por pessoa (STILL, 2000). Além disso, existem pessoas que, por características especiais, irão requerer mais espaço para seu deslocamento e passagem, tais como pessoas que utilizam muletas, cadeiras de rodas ou que transportam crianças (PANERO; ZELNIK, 1998).

No modelo deste trabalho considera-se o corpo como simétrico, de formato quadrado, sendo constituído por $45 \mathrm{~cm} \mathrm{x} 45 \mathrm{~cm} \mathrm{ou} \approx 0,20 \mathrm{~m}^{2} \mathrm{de}$ área (25 elementos de $9 \mathrm{~cm}$ x $9 \mathrm{~cm}$ cada). As pessoas poderão ser denominadas deste ponto em diante alternativamente como autômatos fuzzy ou simplesmente autômatos. Na Figura 4 se apresentam a representação de uma pessoa (ou de sua área de influência física) e um exemplo de um ambiente construído gerado pelo programa Fuga. Todas as representações de ambientes neste trabalho se darão sempre por vistas de topo. Não se considerarão pessoas com necessidades especiais.

\section{Velocidade de deslocamento}

A determinação da velocidade de deslocamento também varia de forma extensiva em relação à população, e o mesmo indivíduo pode apresentar diferentes velocidades dependendo da situação, tais como: idade, condição física e gênero, familiaridade da rota; finalidade do encaminhamento; comprimento do percurso; características da rota (largura de passagem, tipo de pavimentação, densidade e sentido do fluxo, mudança de nível); condições de visibilidade; condições meteorológicas; se sozinho ou acompanhado; e aspectos mentais diversos (ABLEY, 2007).

Neste trabalho considera-se a velocidade normal de deslocamento segundo o gráfico da Figura 5, adaptado das curvas gerais de velocidade de deslocamento para diversos grupos de pessoas (THOMPSON; MARCHANT, 1995a). Para determinação da distância entre pessoas, existe dentro do programa um algoritmo que calcula, a cada iteração, a distância entre um autômato e outro, a sua frente, que se encontra na mesma rota de encaminhamento.

Figura 4 - Exemplo da representação no programa Fuga de uma pessoa (à esquerda) e de um ambiente geral (15 m x 15 m, 6 compartimentos e 1 saída) com seus elementos (à direita)
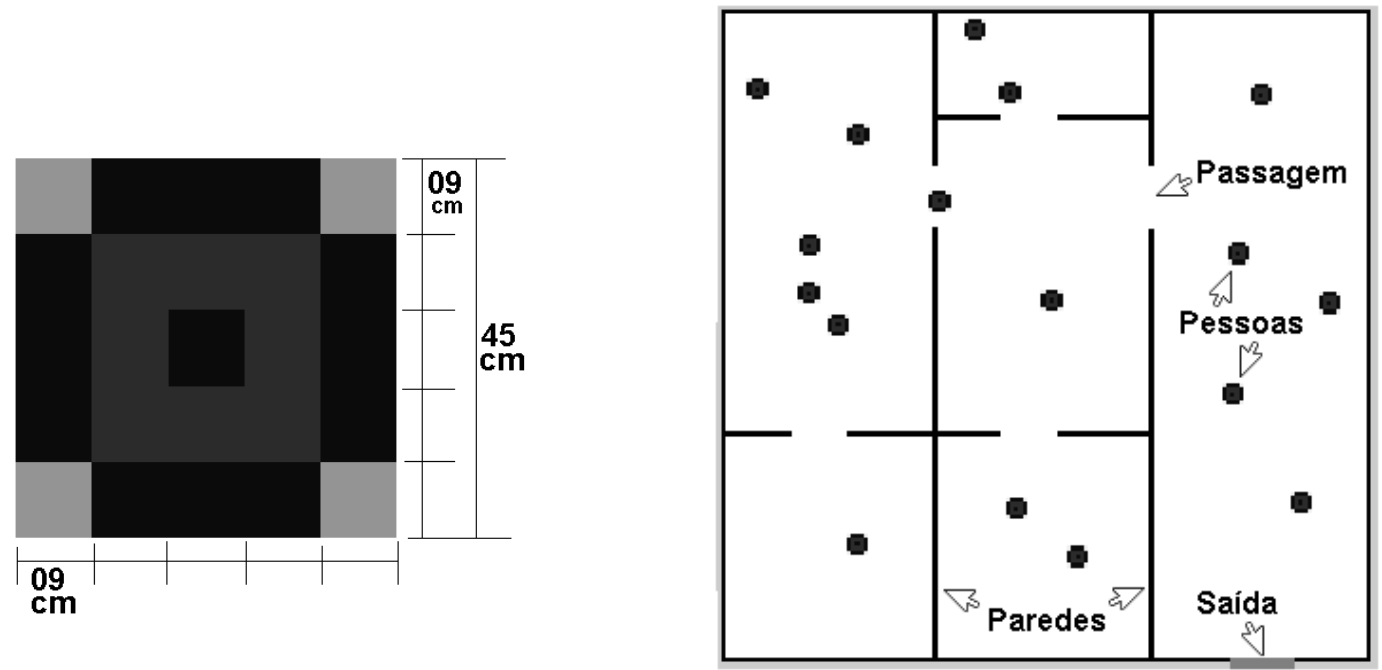

Simulação da movimentação de pessoas em situações de emergência: aspectos ergonômicos e computacionais com 
Figura 5 - Relação típica da velocidade de deslocamento de uma pessoa em função da distância a outra pessoa à frente

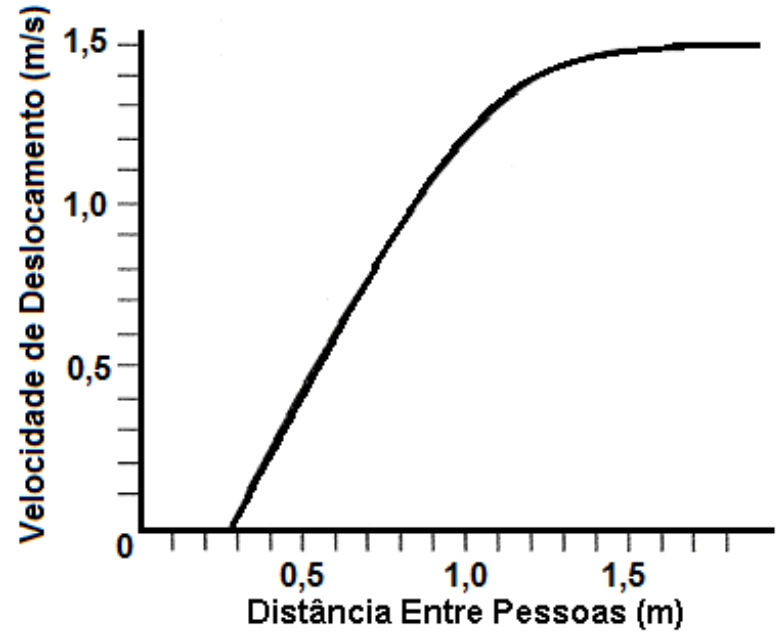

Fonte: adaptado de Thompson e Marchant (1995a).

Para exemplo de como esse comportamento da velocidade pode influenciar no perfil de deslocamento, apresenta-se na Figura 6 uma imagem de uma simulação em que 300 pessoas localizadas num canto de um corredor querem se locomover rumo a uma saída localizada no canto oposto. As pessoas localizadas mais à direita, por não possuírem pessoas a sua frente, se locomovem mais rapidamente que as demais. Entretanto, quando a distância entre as da frente e as imediatamente atrás atinge certo valor, estas também passam a se deslocar mais rapidamente, e assim sucessivamente, criando colunas de deslocamento (efeito emergente).

\section{Tomada de decisão}

A tomada de decisão relativa ao melhor percurso será feita por um sistema fuzzy com seis grandezas de entrada e uma de saída, a saber.

\section{Distância aparente}

Quando uma pessoa idealiza ou antecipa mentalmente um percurso, o faz baseado em vários fatores. Geralmente, o principal fator, que será aqui parametrizado, é o de se realizar o percurso na menor distância aparente ou perceptível possível (ou na maior velocidade para atingir o objetivo com o mesmo ou menor esforço físico).

Como o ambiente é aqui representado por uma matriz, desenvolveu-se um algoritmo computacional de inteligência artificial do tipo pathfinder (BRAGA; CAMARGO; ALMEIDA,
2012) apropriado para esse ambiente discreto, indicando o melhor caminho idealizado entre o ponto inicial (onde a pessoa está) e o ponto final (onde a pessoa deseja chegar), que, no caso do escopo deste trabalho, será a saída do ambiente. O algoritmo criado tem relativo baixo custo computacional (diretamente proporcional à área do ambiente), funcionamento automático (independe de intervenção humana), independência da geometria ou design do ambiente, assim como do posicionamento ou quantidade de saídas (adaptabilidade), e sempre fornece o melhor valor possível (ou pelo menos um deles, no caso de vários melhores percursos). Esse algoritmo específico não considera a influência do conjunto das pessoas, mas somente dos obstáculos fixos e geometria do ambiente construído (como se a pessoa que vai se movimentar estivesse sozinha).

Esse algoritmo cria outra matriz da mesma dimensão da matriz ambiente geral, com cada elemento contendo o menor número de elementos de matriz entre aquele elemento e o destino desejado. Deste número se determina uma das grandezas de entrada do sistema fuzzy, chamada de distância aparente (DA), que poderá apresentar os seguintes valores:

$\mathrm{DA}=0$, se piorar (ou aumentar) a distância aparente;

$\mathrm{DA}=0,5$, se mantiver a mesma distância aparente; e

$\mathrm{DA}=1$, se a direção verificada indicar uma casa com menor distância aparente que a atual ocupada. 
Figura 6 - Exemplo de um possível impacto desta velocidade sobre o perfil de deslocamento

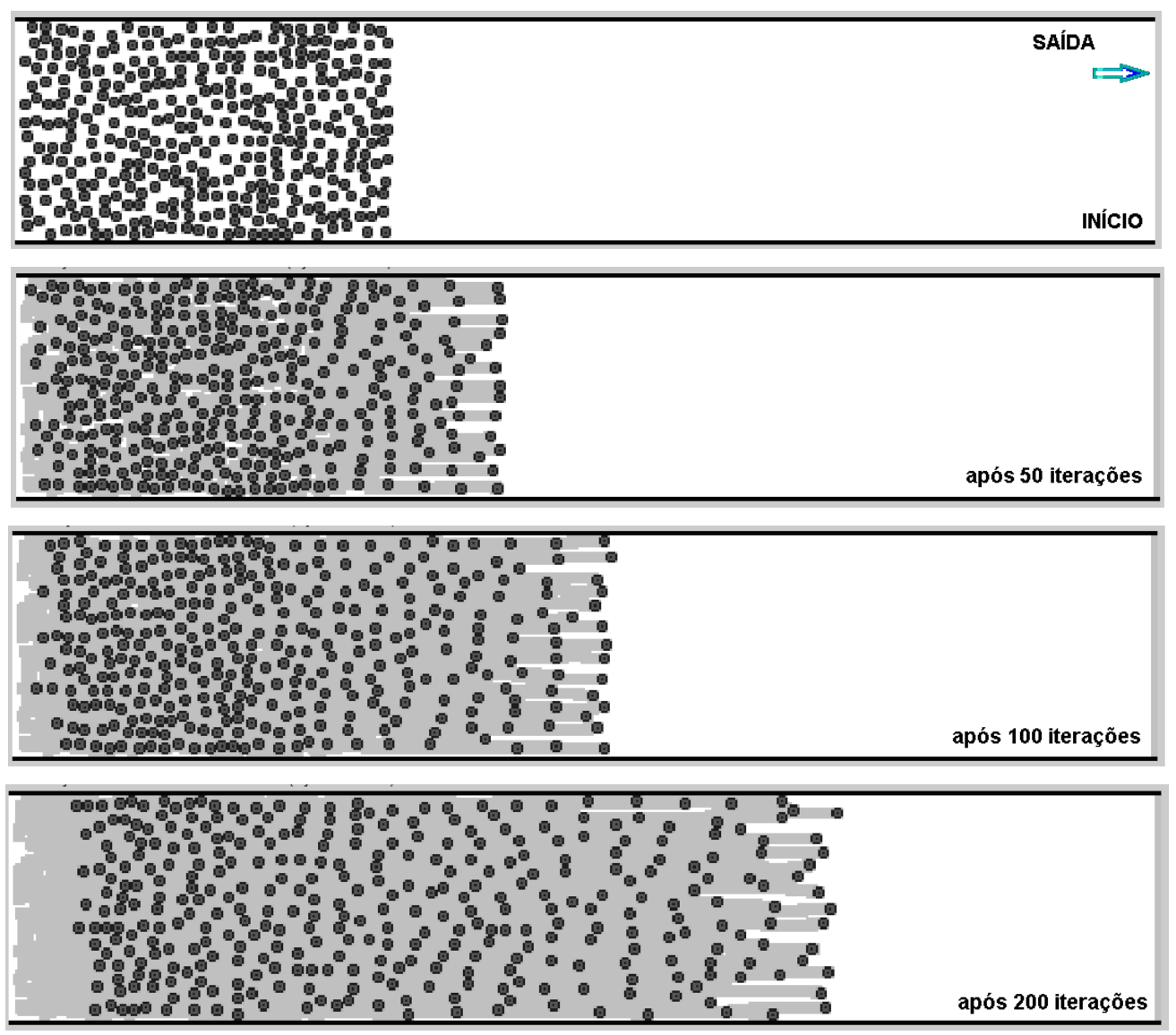

\section{Rota preferencial}

Apesar de as pessoas criarem mentalmente o percurso relacionado com a DA, acontecem normalmente situações onde existem vários percursos com a mesma DA. Assim, como vários melhores percursos são geralmente possíveis, se tem de definir, antes da simulação, algum critério de seleção coerente com o que poderia ser adotado por uma pessoa nessa situação, ou seja, estabelecer uma rota preferencial. Para tal, foram criadas duas possibilidades distintas de seleção prévia, denominadas de método euclidiano e método diagonal, assim como possibilidades mistas entre esses métodos, gerados por meio da matriz ambiente geral, mediante um algoritmo especificamente desenvolvido para tal (BRAGA; CAMARGO; ALMEIDA, 2012). Como ilustração, na Figura 7 se apresentam, para o mesmo ambiente construído, exemplos de rotas preferenciais obtidas pelos distintos métodos e um exemplo de como seria a efetiva movimentação de uma pessoa segundo esses diferentes métodos, a partir de uma mesma posição inicial. Entretanto, ressalta-se que, apesar de essa rota preferencial de fuga sempre atingir a saída, as pessoas, principalmente quando em grupo, não seguem diretamente as rotas indicadas por esses métodos, pois o efetivo percurso sofre diversas outras influências. Assim, essa rota será uma componente dentro do sistema fuzzy.

Estabelece-se, então, outra variável de entrada do sistema fuzzy, denominada de rota preferencial (RP), que poderá apresentar os seguintes valores:

$\mathrm{RP}=0$, se direção verificada for oposta à indicada pela direção da seta;

$\mathrm{RP}=0,5$, se direção verificada for ortogonal à indicada; e

$\mathrm{RP}=1$, se a direção verificada coincidir com a direção indicada.

\section{Nível de estresse}

Segundo estudos citados por Staal (2004), a habilidade de uma tomada de decisão varia com o nível de estresse ao qual a pessoa está submetida, conforme um " $U$ " invertido (Figura 8), ou seja, segundo essa hipótese, as pessoas tomam melhores decisões quando sujeitas a um nível de estresse intermediário. 
Figura 7 - Representações de um ambiente com diferentes opções de rota preferencial e como seria a movimentação de uma pessoa se sujeita somente a esse efeito

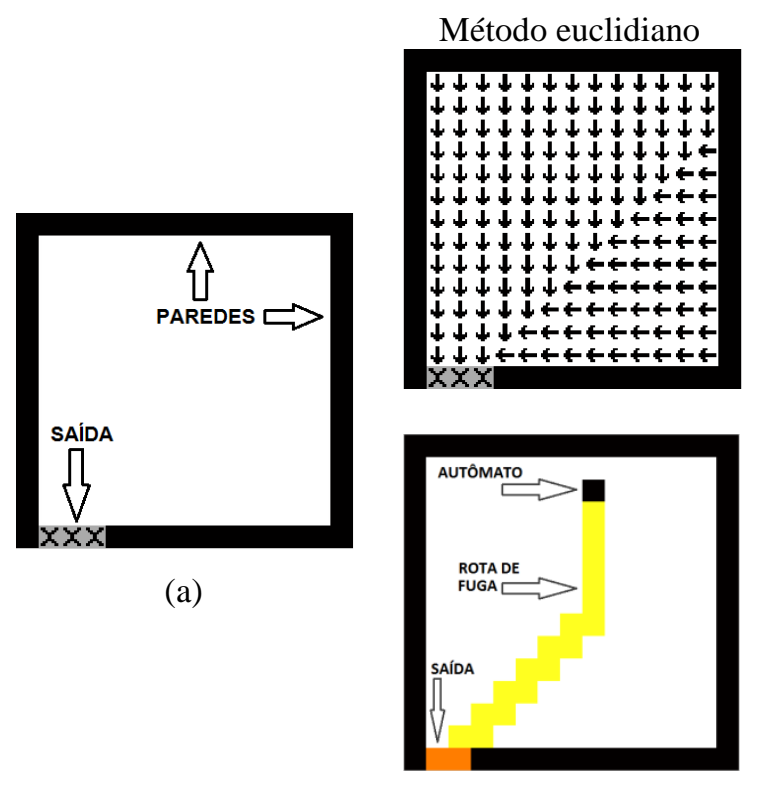

(b)

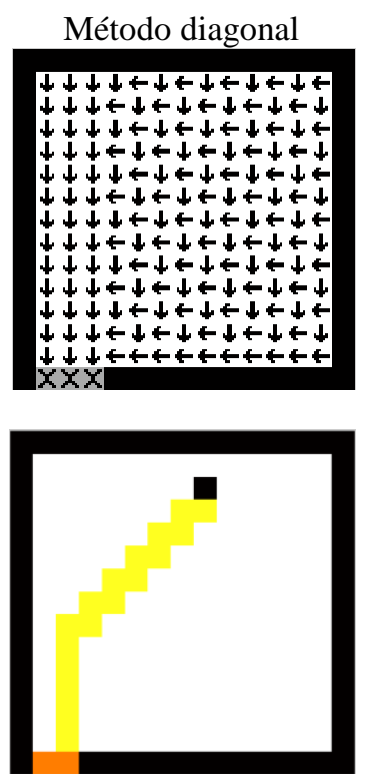

(c)

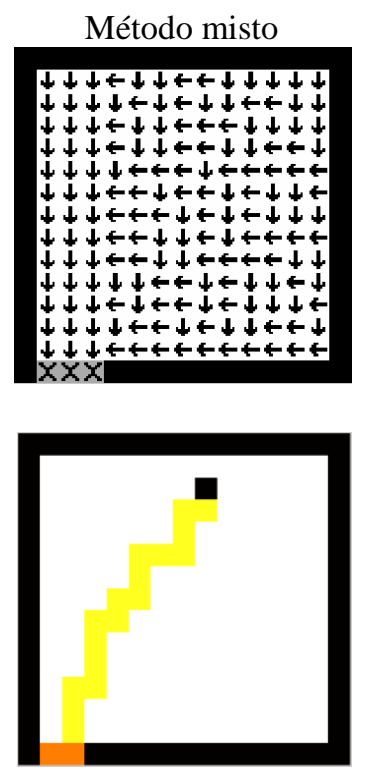

(d)

Figura 8 - Hipótese do $U$ invertido relacionando a habilidade em se tomarem decisões com o nível de estresse

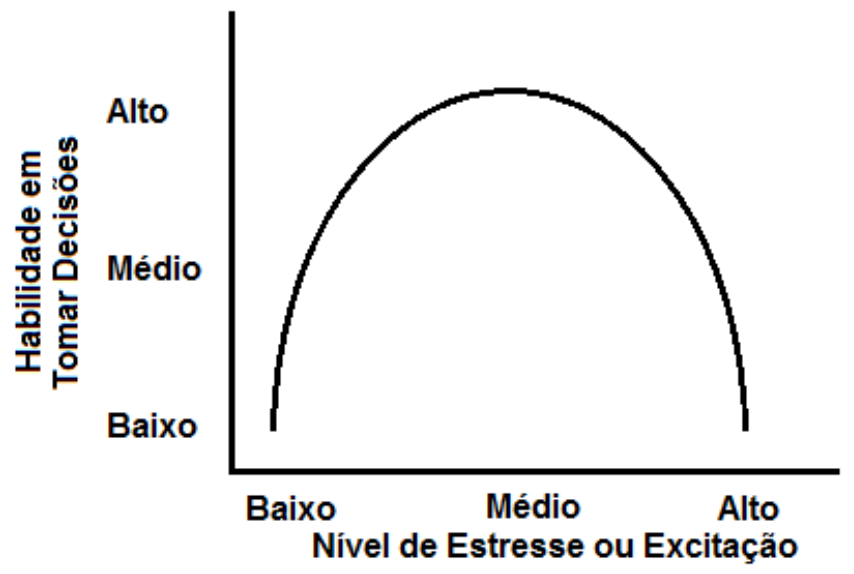

Fonte: adaptado de Staal (2004).

O nível de estresse será fixado antes de cada simulação. Assim, é estabelecida mais uma variável de entrada do sistema fuzzy, denominada de nível de estresse (NE), que poderá ter os seguintes valores:

$\mathrm{NE}=0$, para situações de médio estresse;

$\mathrm{NE}=\mathrm{DA}$, para baixo ou alto estresse; $\mathrm{e}$

$\mathrm{NE}=\operatorname{rand}(1)$, para situações de muito alto estresse.

Onde $\operatorname{rand}(1)$ significa um número real aleatório entre 0 e 1 .

Convém ressaltar que um mesmo estímulo pode provocar um nível de estresse diferenciado em cada pessoa, ou seja, uma situação de risco específica pode causar um estresse muito elevado em certo indivíduo, mas um nível de estresse médio em outro (um cidadão comum versus um bombeiro militar, por exemplo). Além disso, existe um nível individual elevado de estresse que, ao ser atingido, inicia nas pessoas um processo de perda dos acordos sociais ou posturas normalmente praticadas, chamado de comportamento não adaptativo (PAN et al., 2007). O modelo permite variar o nível de estresse, mas sem atingir esse comportamento não adaptativo.

68 Braga, H. C.; Moita, G. F.; Camargo, F.; Almeida, P. E. M. de; 


\section{Efeito zona de conforto}

Por motivos comportamentais, procura-se evitar, quando possível, andar demasiadamente perto de paredes e obstáculos. Isso está relacionado a fatores como busca de segurança, já que um choque eventual com um obstáculo pode ser evitado se a movimentação ocorrer a certa distância dele (STILL, 2000), ou a fatores sociais, como uma busca por um espaço de conforto (PAN et al., 2007). O cálculo dessas áreas de vizinhanças é feito por um algoritmo específico dentro do programa.

Assim, para essa caracterização são criadas duas novas variáveis de entrada do sistema fuzzy, denominadas de efeito parede (EP) e efeito autômato (EA), que podem ter os seguintes valores:

$\mathrm{EP}=0$, se posição for vizinha imediata a uma parede (grande efeito repulsivo);

$\mathrm{EP}=0,5$, se posição for de dois elementos de matriz afastada de alguma parede; e

$\mathrm{EP}=1$, se posição for de três elementos de matriz ou mais afastada de alguma parede (nenhum efeito repulsivo);

$\mathrm{EA}=0$, se houver um autômato vizinho na direção até seis elementos de matriz de distância; e

$\mathrm{EA}=1$, se a direção estiver desobstruída.

\section{Efeito inércia}

Quando se está movimentando em uma direção, ocorre certa tendência natural a permanecer nessa direção. É como se as pessoas tendessem a manter, mesmo que por um período curto, uma constância no sentido do movimento previamente desenvolvido. Essa tendência pode ser marcante a ponto de criar zonas de baixa densidade populacional (vazios) em algumas interseções (STILL, 2000). Para essa caracterização, foi criada uma nova variável de entrada do sistema fuzzy, denominada de efeito inércia (EI), que pode ter os seguintes valores:

$\mathrm{EI}=0$, se ocorrer na direção oposta à última movimentação realizada;

$\mathrm{EI}=0,5$, se ocorrer na direção ortogonal à última realizada; e

$\mathrm{EI}=1$, se movimento mantiver a mesma direção.

\section{Qualidade da rota}

A qualidade da rota $(\mathrm{QR})$ é a variável de saída do sistema fuzzy, sendo uma função dinâmica $f u z z y$ de todas as variáveis anteriormente apresentadas. Ela indica a rota a ser efetivamente tomada de movimentação, conforme as Equações 1, 2 e 3.

$$
\begin{array}{ll}
\mathrm{QR}_{k}=f_{\text {Fuzzy }}\left(\mathrm{DA}_{k}, \mathrm{EP}_{k}, \mathrm{NE}_{k}, \mathrm{RP}_{k}, \mathrm{EI}_{k}, \mathrm{EA}_{k}\right) & \text { Eq. } 1 \\
\mathrm{QR}_{k e}=\max \left(\mathrm{QR}_{k}\right) & \text { Eq. } 2 \\
k e=k \forall_{Q R_{k e}=Q R_{k}} & \text { Eq. } 3
\end{array}
$$

Onde:

$f_{\text {Fuzzy }}=$ função resposta característica do sistema fuzzy;

$k=$ opções de movimentação, ou seja, L (esquerda), U (acima), R (direita) e D (abaixo);

$k e=\mathrm{a}$ opção de movimentação efetivamente escolhida;

$\mathrm{QR}_{k}=$ cada um dos $\mathrm{QR}$ para cada uma da $k$ opções de movimentação calculados pelo sistema fuzzy; e

$\mathrm{QR}_{k e}=\mathrm{QR}$ da rota efetivamente escolhida.

\section{Sistema Fuzzy}

A cada iteração para cada autômato, o sistema fuzzy fará a leitura das seis grandezas de entrada e fornecerá a grandeza de saída independentemente para as quatro opções de movimentação (esquerda, acima, direita e abaixo), e, então, como já mencionado, o programa selecionará a opção mais vantajosa (de maior QR). Na Figura 9, o sistema fuzzy estabelecido é mostrado.

As grandezas do sistema fuzzy foram estabelecidas como tendo o mesmo universo de discurso [0 a 1$]$ $\mathrm{e}$ as mesmas três funções de pertinência no formato triangular, com os seguintes termos primários: Z-zero, M-mediano e P-positivo. Como exemplo do processo de inferência do sistema fuzzy criado, são apresentados na Figura 10 a visualização das funções de pertinência triangulares usadas, o conjunto de regras estabelecido, um cálculo de $\mathrm{QR}$ considerando todas as grandezas de entrada como 0,5 e um gráfico com a variação do $\mathrm{QR}$ em função de $\mathrm{RP} e$ NE.

\section{Relatórios e gráficos de saída do programa Fuga}

Durante e após a simulação, o programa gera uma série de relatórios e gráficos. Entre eles se destacam:

(a) características da simulação realizada (data e horário, identificação do ambiente simulado, número de pessoas);

(b) tempos gastos para abandono do ambiente (totais e parciais); 
(c) número de iterações para abandono do ambiente;

(d) gráfico com o número de pessoas em função do tempo que deixam o ambiente;

(e) gráfico com o fluxo de abandono de pessoas no tempo;

(f) gráficos com o mapa de possibilidade de colisões;

(g) vista de topo, estilizada por setas, representando a matriz rota de fuga criada; e

(h) vista de topo da simulação, identificando as pessoas em sua posição inicial, com as respectivas rotas tomadas para abandono.
É possibilitado o acompanhamento dinâmico da simulação por meio de sua interface gráfica. Simulações com poucos autômatos (50, por exemplo) são rápidas e permitem fácil acompanhamento. Por outro lado, simulações com grande número de autômatos (5.000, por exemplo) requerem várias horas de processamento. $\mathrm{O}$ programa possibilita ao usuário a gravação da simulação, que, posteriormente reproduzida, pode ser acelerada para um acompanhamento facilitado de sua evolução.

Por sua importância, o tempo de escape, o fluxo de abandono e a possibilidade de colisões são discutidos a seguir.

Figura 9 - Representação do sistema fuzzy com a indicação das grandezas de entrada e saída

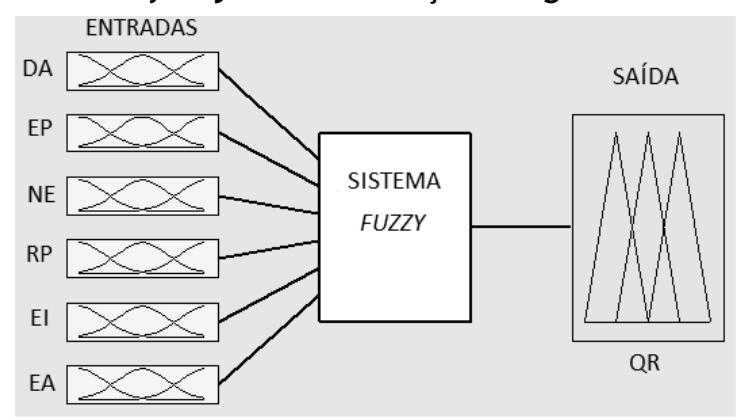

Figura 10 - Exemplos do processamento interno do sistema fuzzy

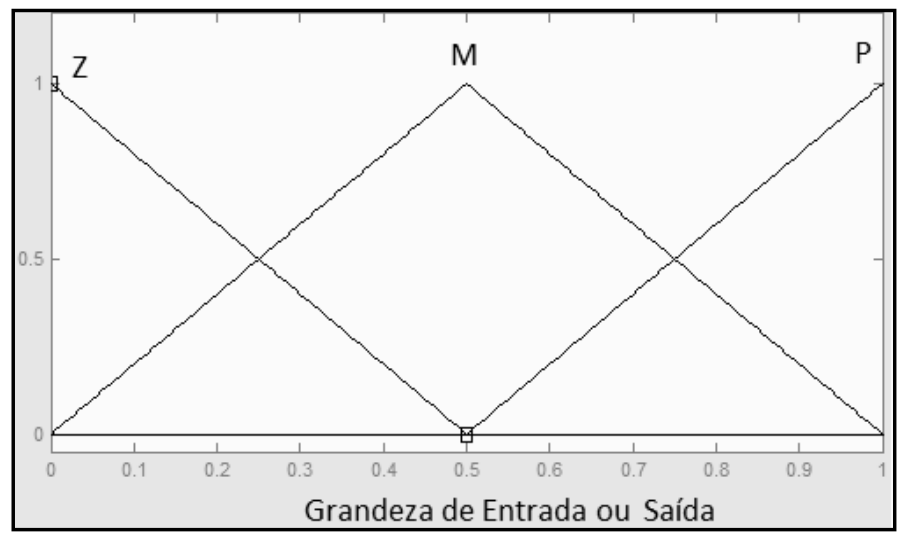

(a) Funções de pertinência e termos primários para todas as grandezas

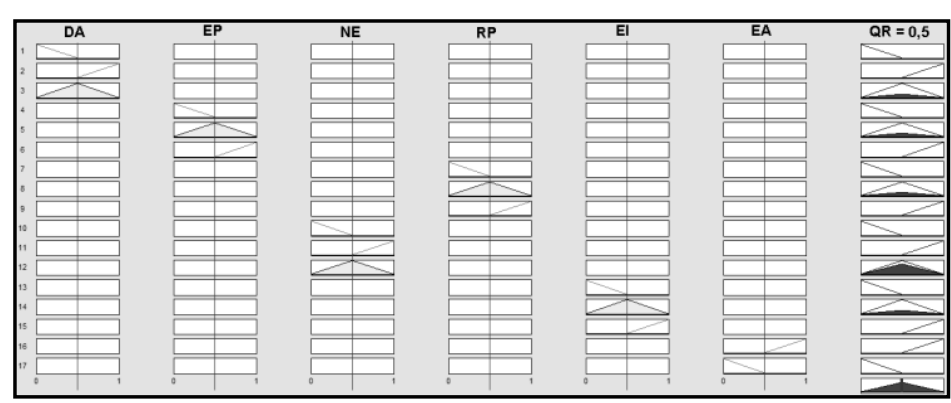

(c) Etapa de inferência

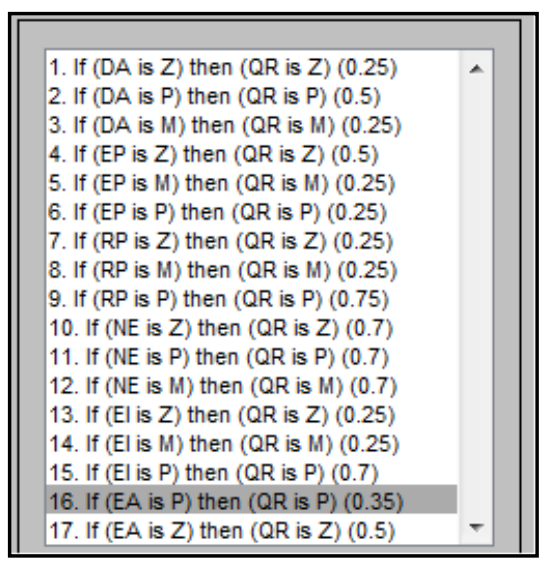

(b) Das normas

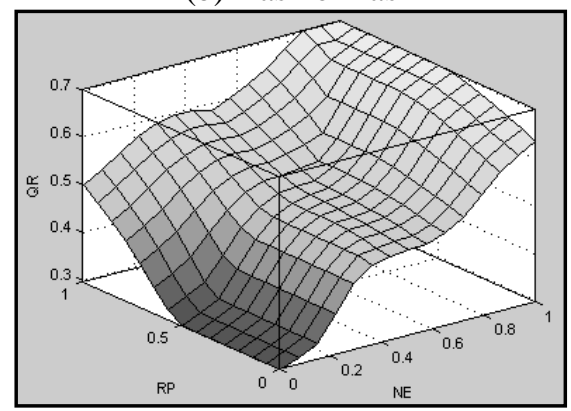

(d) Variação do QR em função de algumas grandezas de entrada

70 Braga, H. C.; Moita, G. F.; Camargo, F.; Almeida, P. E. M. de; 
Tempo de escape: o tempo de escape é normalmente considerado como o somatório de três parcelas: o tempo de percepção, o tempo de reação e o tempo efetivo de movimentação. Essa versão do programa Fuga não considera o tempo de percepção e reação, nem possibilita se variar o tempo de início do movimento de diferentes indivíduos. Assim, todo o tempo de escape a ser referido neste trabalho é do tempo efetivo de movimentação, e, disparada a simulação, todas as pessoas imediatamente se direcionam rumo à saída.

Fluxo do abandono: é uma medida da taxa de desocupação do ambiente. Como o número de pessoas que deixam o ambiente é discreto, os gráficos de fluxo de abandono são elaborados com uma base de tempo também discreta. O programa Fuga gera dois tipos de gráfico de fluxo, denominados de over $1 \mathrm{~s}$ e over $5 \mathrm{~s}$. No tipo over $1 \mathrm{~s}$, a cada segundo o programa conta quantos autômatos saíram do ambiente no último segundo, valor considerado como o fluxo de abandono de pessoas over 1s. Já no tipo over 5s, o programa conta a cada segundo quantos autômatos saíram do ambiente nos últimos 5 segundos, divide esse valor por 5 , e este novo valor é considerado como o fluxo de abandono de pessoas over $5 \mathrm{~s}$. O gráfico de fluxo de abandono do tipo over 5 s é utilizado para estudos da desocupação de ambientes (THOMPSON; MARCHANT, 1995b).

Possibilidade de colisões: a efetiva troca de energia entre as pessoas em abandono assim como a ocorrência de empacotamentos (SCHADSCHNEIDER et al., 2009) não podem ser diretamente verificadas pela versão atual do programa Fuga. Entretanto, o programa fornece o parâmetro possibilidade de ocorrência de colisões entre as pessoas, que pode ser usado como uma inferência dessa troca de energia. A possibilidade de colisão é fornecida em quatro condições: tipo 1, tipo 2, tipo 3 e tipo 4. A possibilidade de colisão do tipo 1 (PCT1) indica quantas vezes rumo à saída as pessoas tiveram sua opção preferencial de deslocamento fornecida pelo sistema fuzzy interrompida por outras pessoas. A possibilidade de colisão do tipo 2 (PCT2) indica quantas vezes rumo à saída as pessoas tiveram sua primeira e segunda opção preferencial de deslocamento interrompida por outras pessoas. A possibilidade de colisão do tipo 3 (PCT3) indica quantas vezes rumo à saída as pessoas tiveram sua primeira, segunda e terceira opção de deslocamento interrompida por outras pessoas. Já a possibilidade de colisão do tipo 4 (PCT4) indica quantas vezes rumo à saída as pessoas tiveram todas as possibilidades de deslocamento interrompidas (caminho totalmente obstruído).
Assim, uma PCT1 baixa indica ausência de possibilidade de ocorrência de colisões ou empacotamento, enquanto uma PCT4 elevada indica uma real possibilidade de confrontos ou choques entre os ocupantes durante a desocupação.

\section{Resultados}

O modelo aqui proposto foi implementado na plataforma do ambiente MatLab ${ }^{\circledR}$ (versão 7.9.0 /R2009b), utilizando-se do seu Toolkit Fuzzy já instalado e de suas ferramentas gráficas. O programa computacional desenvolvido, Fuga, está em sua versão 0.6 .

\section{Validação do modelo}

Para validação são realizadas simulações, e seus resultados comparados com valores obtidos da literatura por outros pesquisadores. Entre todos os modelos existentes, talvez um dos mais empregados e comentados fora do ambiente de seus criadores seja o Simulex (THOMPSON; MARCHANT, 1995a, 1995b). É comercialmente disponibilizado $^{2}$ para pesquisadores e projetistas que querem estudar questões relacionadas ao escape ou seu relacionamento com o projeto arquitetônico. Este modelo será usado como base para comparação e validação inicial do programa Fuga.

\section{Teste 1}

$\mathrm{Na}$ apresentação inicial do Simulex, seus autores realizaram uma validação do então novo modelo comparando os valores de fluxo de escape com valores já consagrados em trabalhos experimentais ou em códigos. Assim, no presente estudo essa simulação foi repetida, e o resultado obtido pelo Fuga comparado com o resultado original (THOMPSON; MARCHANT, 1995b). O ambiente dessa simulação é composto de uma passagem de tamanho variável, com 50 pessoas ocupando uma área formada por um quadrado de cerca de $5 \mathrm{~m}$ x $5 \mathrm{~m}$, com uma passagem ou saída central.

Para o cálculo do fluxo médio de autômatos se utilizou a curva de fluxo over $5 \mathrm{~s}$, obtida desprezando-se o primeiro e último pontos, já que estes possuem valores não condizentes com a real capacidade da abertura (equivalente a um regime transiente). A supressão dos valores da parte inicial e final da simulação na curva de fluxo over $5 \mathrm{~s}$ também foi realizada por Thompson e Marchant (1995b) em seus cálculos originais. Na Figura 11 é apresentada uma visão gerada pelo programa Fuga

\footnotetext{
${ }^{2}$ Disponível em:

<http://www.firemodelsurvey.com/pdf/Simulex_2001.pdf>.
} 
do ambiente simulado e um gráfico comparando os resultados obtidos com o Simulex para uma largura de abertura variando entre aproximadamente 1,0 $\mathrm{m}$ e 2,7 $\mathrm{m}$. Qualitativamente, a coerência entre os dois modelos foi muito satisfatória.

\section{Teste 2}

Ko (2003), utilizando o Simulex, realizou algumas simulações que foram repetidas pelo programa Fuga, para comparação dos resultados. Inicialmente, esse autor gerou um ambiente quadrado, sempre com 1.003 autômatos, sem repartições internas, de área variável $(500,1.000$ e $2.000 \mathrm{~m}^{2}$ ), com uma única saída. Os ocupantes foram uniformemente distribuídos nesses ambientes antes das simulações, para verificação do tempo de escape. Posteriormente, Ko (2003) gerou um ambiente em forma de auditório (cerca de $10,5 \mathrm{~m} \times 8,5 \mathrm{~m}$ ), com diversas obstruções internas devido a cadeiras, e com duas saídas em lados extremos de uma mesma parede (este ambiente é uma cópia de um ambiente real que Ko utiliza em seus estudos). Ko (2003) considerou, para esse auditório, populações de 56 e 63 ocupantes. Na Figura 12 podem ser vistas representações dos ambientes geradas pelo programa Fuga, e na Tabela 1, uma comparação entre os resultados obtidos, que foram coerentes entre si.

Figura 11 - Imagens da simulação (à esquerda) e da comparação dos valores obtidos pelo Fuga com o Simulex (à direita)

\begin{tabular}{ll|l|l|}
\hline $\begin{array}{l}\text { Imagem do } \\
\text { Inicio da } \\
\text { Simulação }\end{array}$ & \\
\hline \hline Durante a & & \\
Simulação & & \\
\hline
\end{tabular}

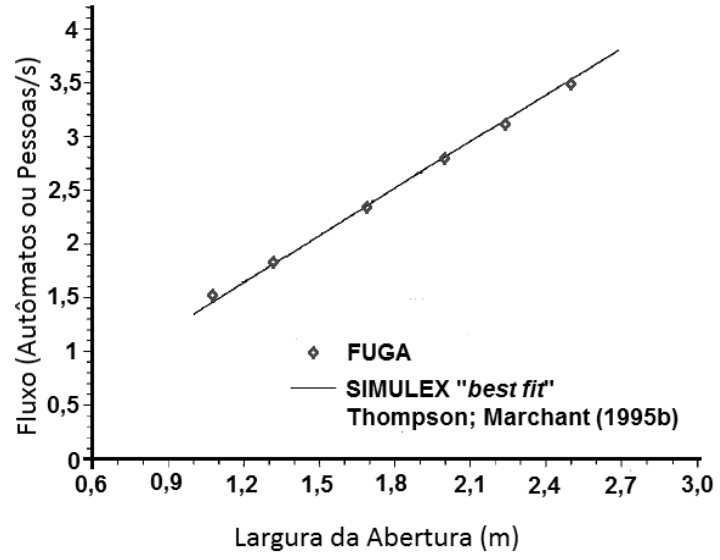

Figura 12 - Imagens de simulações geradas pelo programa Fuga de ambientes apresentados por Ko (2003) - à esquerda e centro do ambiente quadrado com $500 \mathrm{~m}^{2}$, no início e durante a simulação respectivamente, e à direita, para o auditório com 56 ocupantes
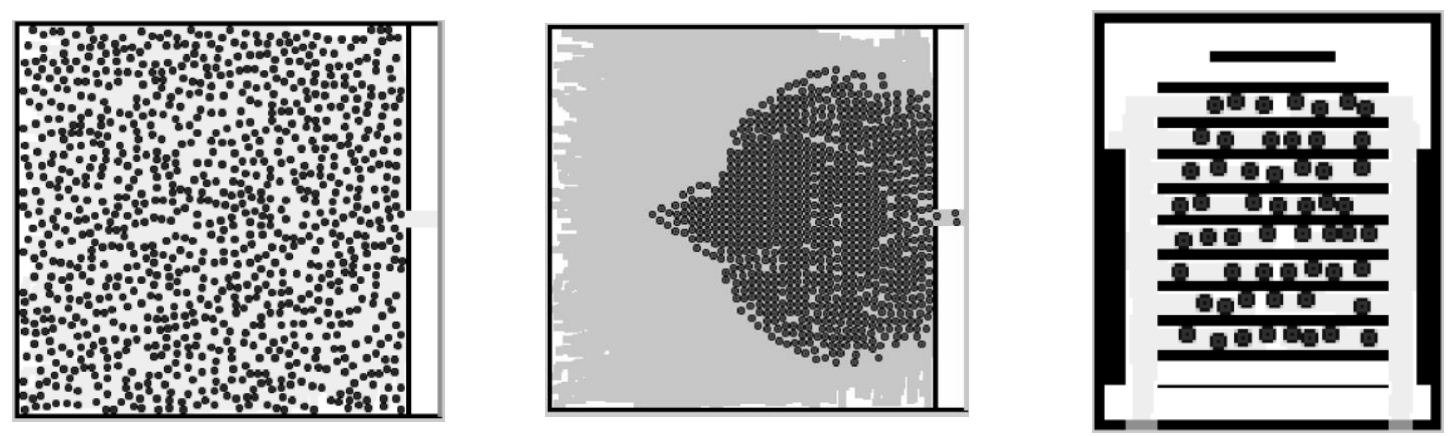

Tabela 1 - Comparação entre os valores obtidos com o Simulex (KO, 2003) e o Fuga

\begin{tabular}{c|c|c|c|c|c}
\hline \multirow{2}{*}{ Cenário } & \multirow{2}{*}{ População } & \multirow{2}{*}{ Área $\left(\mathbf{m}^{\mathbf{2}}\right)$} & \multirow{2}{*}{$\begin{array}{c}\text { Densidade } \\
\text { (autômatos/m }\end{array}$} & & \multicolumn{2}{c}{ Tempo Evacuação $(\mathbf{s})$} \\
\cline { 5 - 6 } & & & Simulex & Fuga \\
\hline Salão Quadrado & 1.003 & 500 & 2,0 & 506 & $510 \pm 6$ \\
Salão Quadrado & 1.003 & 1.000 & 1,0 & 537 & $521 \pm 7$ \\
Salão Quadrado & 1.003 & 2.000 & 0,5 & 538 & $536 \pm 7$ \\
Auditório & 56 & $\approx 89$ & $\approx 0,6$ & 31 & $31,5 \pm 0,8$ \\
Auditório & 63 & $\approx 89$ & $\approx 0,7$ & 40 & $40 \pm 0,9$ \\
\hline
\end{tabular}

72 Braga, H. C.; Moita, G. F.; Camargo, F.; Almeida, P. E. M. de; 


\section{Simulações de ambientes}

Terminada a etapa de validação, são realizadas algumas simulações visando ilustrar como o programa Fuga pode ser utilizado como ferramenta de apoio ao projeto arquitetônico.

\section{Posicionamento ideal da saída de emergência de um ambiente simples}

Considerando um ambiente simples na forma de um quadrado de $10 \mathrm{~m}$ de lado sem divisões internas, são simulados os escapes considerando uma saída de $1,1 \mathrm{~m}$ ou de $3,3 \mathrm{~m}$, para populações de 50, 100, 200 e 250 pessoas. As saídas estão posicionadas no centro da parede, no canto da parede, ou numa posição intermediária entre o centro e o canto. Cada simulação é repetida 10 vezes, e o posicionamento das pessoas é aleatório no ambiente, a cada simulação. Na Figura 13 são apresentados os tempos de escape obtidos, em que se percebe que a saída mais central resulta num tempo de escape menor que o obtido com essa mesma saída posicionada junto a um dos cantos.

\section{Ambientes reais complexos}

Selecionou-se um ambiente real utilizado como instituição de ensino, conforme leiaute apresentado e estudado anteriormente (SOUZA, 2007). Esse ambiente possui $816 \mathrm{~m}^{2}$ (ou cerca de $10^{5}$ elementos quadrados de $9 \mathrm{~cm}$ de lado). Foram realizadas simulações para abandono desse ambiente para populações de 1, 64 e 288 pessoas, considerando uma única saída, e com 2, 64 e 288 pessoas, considerando duas saídas. Cada simulação foi repetida 10 vezes, com o posicionamento das pessoas sendo aleatório a cada simulação, exceto nas simulações com 1 e 2 pessoas, em que foram posicionadas o mais distante possível das saídas, de forma a se terem parâmetros para comparação com as simulações de maior densidade populacional. Na Figura 14 são mostradas as configurações dos exemplos das simulações, e na Tabela 2 são listados alguns dos resultados obtidos.

Pelos resultados apresentados na Tabela 2 para o tempo de escape, corroborando qualitativamente conclusão de estudo anterior para esse mesmo ambiente e populações (SOUZA, 2007), a existência de uma segunda saída proporciona uma significativa queda no tempo de evacuação do ambiente.

Figura 13 - Tempo para escape de ambiente quadrado com $10 \mathrm{~m}$ de lado e uma saída de emergência de $1,1 \mathrm{~m}$ ou $3,3 \mathrm{~m}$ em distintos posicionamentos

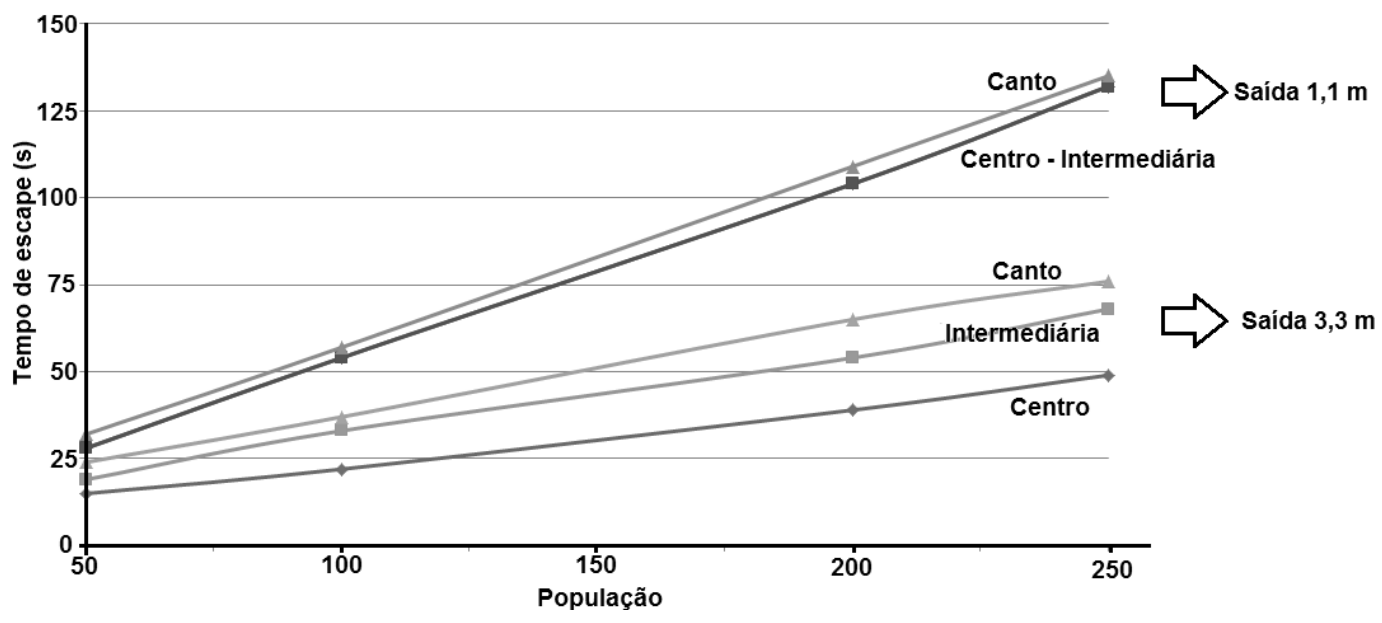


Figura 14 - Imagens de simulações geradas pelo programa Fuga do ambiente apresentado por Souza (2007), com uma saída (acima) e duas saídas (abaixo), com 1 ou 2 pessoas (à esquerda), 64 pessoas (no centro) e 288 pessoas (à direita)
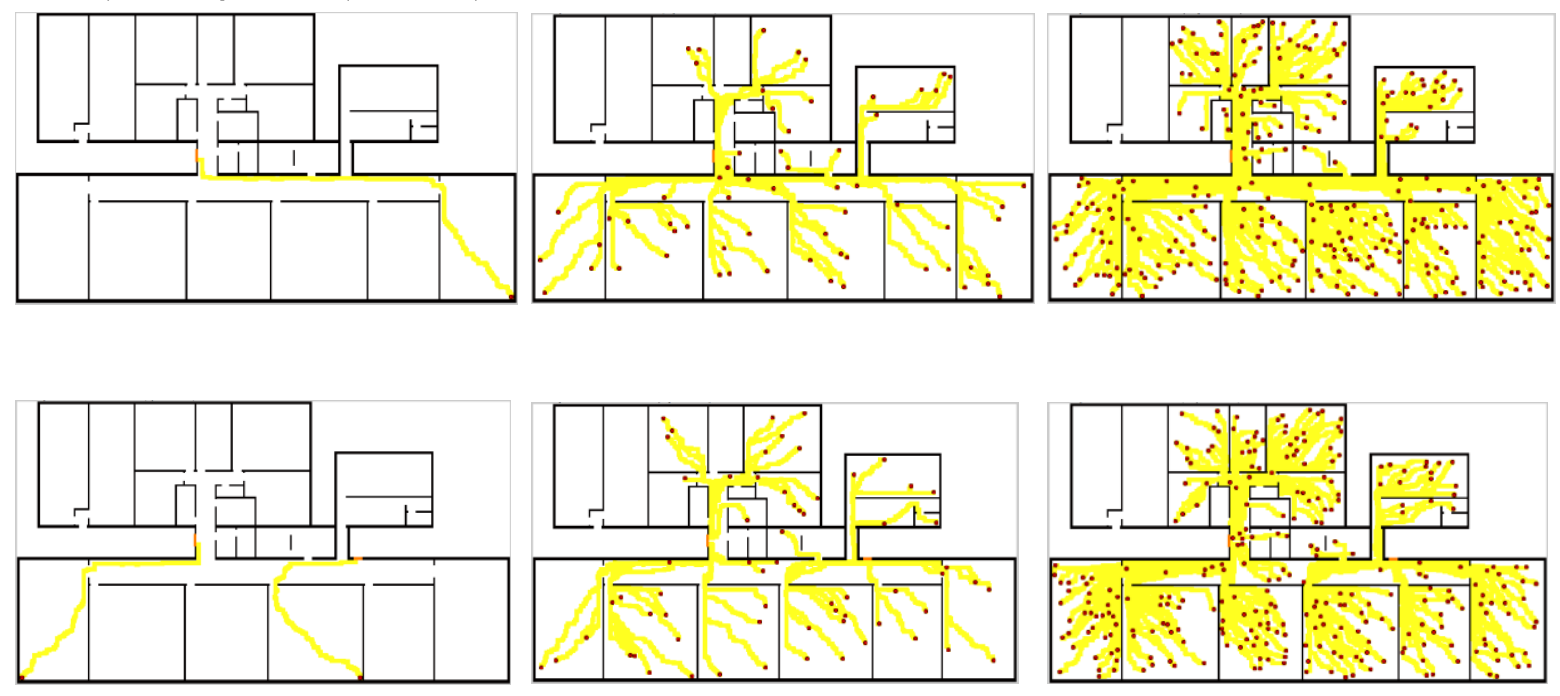

Tabela 2 - Resultados do tempo de evacuação e das possibilidades de colisão

\begin{tabular}{c|c|c|c|c}
\hline \multirow{2}{*}{ Ambiente } & \multirow{2}{*}{ Autômatos } & \multirow{2}{*}{ Tempo Evacuação (s) } & \multicolumn{2}{|c}{$\mathbf{N}^{\circ}$ Possibilidade de Colisões } \\
\cline { 3 - 5 } & & Tipo 01 & Tipo 04 \\
\hline \multirow{3}{*}{ 1 Saída } & 1 & $33 \pm 1$ & 0 & 0 \\
& 64 & $42 \pm 5$ & $1.000 \pm 120$ & $16 \pm 8$ \\
& 288 & $147 \pm 10$ & $29.200 \pm 2.000$ & $4.050 \pm 600$ \\
\hline \multirow{3}{*}{2 Saídas } & 2 & $23 \pm 0,4$ & 0 & 0 \\
& 64 & $30 \pm 3$ & $470 \pm 140$ & $3 \pm 3$ \\
& 288 & $105 \pm 8$ & $15.900 \pm 530$ & $1.580 \pm 150$ \\
\hline
\end{tabular}

O programa Fuga também fornece indicações sobre a possibilidade da ocorrência de colisões em cada escape. Para os ambientes com até 64 ocupantes, pode-se considerar que o escape se dará sem maiores conflitos, pelos reduzidos valores de PCT4 obtidos. Mas, para o ambiente com 288 pessoas, a PCT4 é significativa e implica a ocorrência de possíveis choques durante uma desocupação, principalmente se ocorrer de forma competitiva, e que estes choques se reduzam muito acentuadamente com a introdução da segunda saída.

Adicionalmente, o modelo permite se estudarem efeitos arquitetônicos locais e específicos, tais como o posicionamento de uma porta. Na Figura 15 são colocadas imagens do ambiente da Figura 14 mostrando um conjunto de salas situado na parte superior dele, que desaguam no corredor que vai em direção à saída. Entretanto, umas dessas salas terá dois posicionamentos distintos para a saída, um mais à esquerda, e outro mais à direita (ver setas indicadas na Figura 15 para o posicionamento das saídas dessa sala).
As simulações foram feitas para populações entre 20 e 60 pessoas nas três salas indicadas (não houve pessoas no restante do ambiente). Cada simulação foi repetida 5 vezes, e a distribuição das pessoas foi aleatória em cada simulação. Na Tabela 3 se têm os valores obtidos.

Observando-se os resultados, é possível verificar que a saída mais à direita propicia uma condição de escape que tende a ser mais segura, principalmente pela redução da possibilidade de colisões observadas durante o escape. Uma explicação para esse fato pode ser devido a se terem, no ambiente original, as três salas com suas saídas voltadas praticamente para o mesmo ponto do corredor, e na saída modificada (mais à direita), essa concentração pontual foi reduzida e as pessoas acabaram ocupando melhor o espaço do corredor rumo à saída. A determinação dessa condição mais favorável é facilitada pela utilização do programa computacional Fuga, que se mostra como uma valorosa ferramenta de suporte ao trabalho do projetista. 
Figura 15 - Exemplos de simulações com 60 pessoas, sendo em (a) com a saída de uma sala mais à esquerda, e em (b) com a saída dessa mesma sala mais à direita (ver setas)

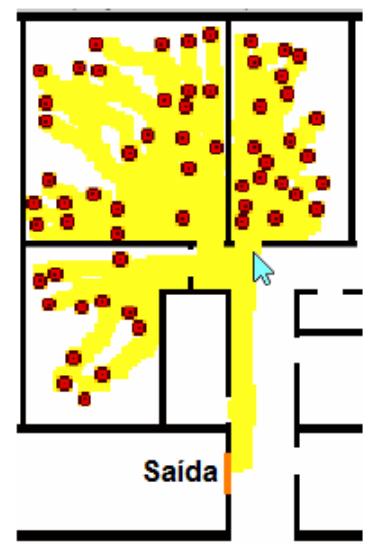

(a)

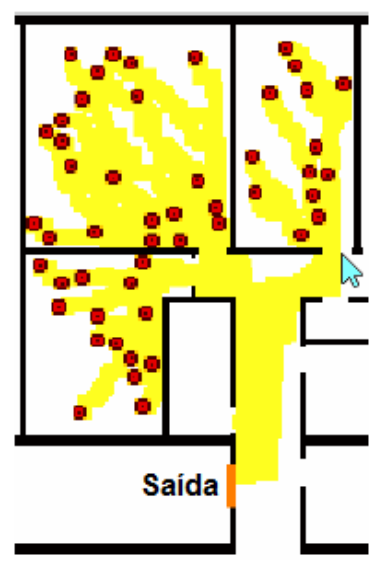

(b)

Tabela 3 - Valores obtidos para o tempo total de evacuação e da possibilidade de colisões nas simulações dos ambientes da Figura 15

\begin{tabular}{c|c|c|c|c}
\hline \multirow{2}{*}{ População } & \multicolumn{2}{|c|}{$\begin{array}{c}\text { Saída à esquerda } \\
\text { (leiaute original) }\end{array}$} & \multicolumn{2}{c}{$\begin{array}{c}\text { Saída à direita } \\
\text { (leiaute modificado) }\end{array}$} \\
\cline { 2 - 5 } & $\begin{array}{c}\text { Tempo } \\
\text { Abandono (s) }\end{array}$ & PCT4 & $\begin{array}{c}\text { Tempo } \\
\text { Abandono (s) }\end{array}$ & PCT4 \\
\hline 20 & $31 \pm 3$ & $30 \pm 30$ & $29 \pm 1$ & $7 \pm 3$ \\
30 & $43 \pm 1$ & $80 \pm 25$ & $38 \pm 1$ & $30 \pm 15$ \\
40 & $54 \pm 1$ & $200 \pm 50$ & $50 \pm 1$ & $100 \pm 30$ \\
50 & $70 \pm 2$ & $430 \pm 100$ & $62 \pm 2$ & $300 \pm 100$ \\
60 & $80 \pm 3$ & $810 \pm 130$ & $74 \pm 3$ & $570 \pm 180$ \\
\hline
\end{tabular}

\section{Conclusões}

Apresentou-se um modelo celular para a simulação da movimentação humana durante o abandono de ambientes construídos em situações de emergência, o qual foi devidamente implementado na forma de um programa computacional denominado Fuga. Como diferencial desse modelo em relação aos já desenvolvidos, há o emprego da ergonomia e da Lógica Fuzzy como seus principais paradigmas. A utilização dos preceitos ergonômicos como balizadores do comportamento humano propiciou uma modelagem mais realista e, ao mesmo tempo, simples e objetiva. Já a Lógica Fuzzy mostrou ser uma ferramenta de inteligência computacional factível de ser utilizada nesse contexto e capaz de emular em certo grau uma tomada de decisão humana, mesmo se essa decisão for feita se utilizando de parâmetros quantitativos e qualitativos. Esse modelo foi validado pela comparação de seus resultados com o obtido por outros autores. Conforme exemplos apresentados, esse programa pode ser utilizado na concepção de ambientes construídos mais seguros e no apoio ao projeto arquitetônico de ambientes reais, de uma forma que dificilmente poderia ser obtida pela aplicação direta das normas e códigos prescritivos existentes. Assim, o programa é uma valorosa ferramenta de apoio ao projetista.

Apesar dos resultados positivos obtidos na implementação do presente modelo, são diversos os desafios futuros necessários para seu aprimoramento. Podem ser citados a substituição da grandeza qualitativa da possibilidade de ocorrência de colisões entre pessoas por outra grandeza quantitativa, a capacidade de simular ambientes de vários andares (inclusão da movimentação sobre escadas e rampas) e a individualização dos comportamentos como os próximos passos a serem desenvolvidos.

\section{Referências}

ABLEY, S. Walkability Tools Research: variables, collection and methodology. New Zeland: Land Transport New Zealand, 2007.

ALMEIDA, P. E. M.; EVSUKOFF, A. G.

Sistemas Fuzzy. In: REZENDE, S. O. (Coord.).

Sistemas Inteligentes: fundamentos e aplicações. Barueri: Manole, 2003. cap. 7. 
BRAGA, H. C.; CAMARGO, F.; ALMEIDA, P. E. M. Fuga: algoritmo heurístico para simulação do melhor caminho inicial para escape em ambientes gerais construídos. In: ENCONTRO MINEIRO DE ENGENHARIA DE PRODUÇÃO, 8., Itajubá, 2012. Anais... Juiz de Fora, 2012. v. 1.

CARTER, R. O Livro de Ouro da Mente. Rio de Janeiro: Ediouro, 2003.

CLARET, A. M.; MATTEDI, D. L. Estudo da Prescritividade das Normas Técnicas Brasileiras de Segurança Contra Incêndio. Rem: Revista Escola de Minas, v. 64, n. 3, p. 265-271, jul./set. 2011.

CUCCI NETO, J. Aplicações da Engenharia de Tráfego na Segurança dos Pedestres. 1996. 188 f. Dissertação (Mestrado em Engenharia de Transportes) - Escola Politécnica, Universidade de São Paulo, São Paulo, 1996.

EDELMAN, G. E. Biologia da Consciência: as raízes do pensamento. Lisboa: Instituto Piaget, 1992. (Coleção Epigénese e Desenvolvimento, v. 13).

GOLDSTONE, R.; ROBERTS, M. E. SelfOrganized Trail Systems in Groups of Humans. Complexity, v. 11, n. 8, p. 43-50, jul./aug. 2006.

HELBING, D.; FARKAS, I.; VICSEK, T. Simulating Dynamical Feature of Escape Panic. Nature, v. 407, p. 487-490, sep. 2000.

IIDA, I. Ergonomia no Projeto de Edifícios e Espaços Públicos. In: IIDA, I. Ergonomia: projeto e produção. 2. ed. São Paulo: Edgard Blücher, 2010.

KNAUSS, P. A Cidade Como Sentimento: história e memória de um acontecimento na sociedade contemporânea: o incêndio do Gran Circus NorteAmericano em Niterói, 1961. Revista Brasileira de História, v. 27, n. 53, p. 25-54, jan./jun. 2007.

KO, S. Y. Comparison of Evacuation Times Using Simulex and EvacuatioNZ Base on Trial Evacuations. 2003. 155 f. Dissertação (Master in Engineering in Fire Engineering) - University of Canterbury, New Zeland, 2003.

KOBES, M. et al. Building Safety and Human Behavior in Fire: a literature review. Fire Safety Journal, v. 45, n. 1, p. 1-11, jan. 2010.

KULIGOWSKI, E. D. Predicting Human Behavior During Fires. Fire Technology, v. 49, n. 1, p. 101120, jan. 2013.

KULIGOWSKI, E. D.; PEACOCK, R. D. A Review of Building Evacuation Models. NIST, 2005. Technical Note 1471.
MATURANA, H.; VARELA, F. J. A Árvore do Conhecimento: as bases biológicas da compreensão humana. 8. ed. São Paulo: Palas Athena, 2010.

NUNES, I. L. Handling Human-Centered Systems Uncertainty Using Fuzzy Logics: a review. The Ergonomics Open Journal, v. 3, p. 38-48, jun. 2010.

ONO, R. Parâmetros Para Garantia da Qualidade do Projeto de Segurança Contra Incêndio em Edifícios Altos. Ambiente Construído, Porto Alegre, v. 7, n. 1, p. 97-113, jan./mar. 2007.

PAN, X. et al. A Multi-Agent Based Framework For the Simulation of Human and Social Behaviors During Emergency Evacuations. AI and Society, v. 22 , n. 2, p. $113-132$, oct. 2007.

PANERO, J.; ZELNIK, M. Las Dimensiones Humanas en los Espacios Interiores. 8. ed. México: G. Gili, 1998.

PELECHANO, N.; ALLBECK J.; BADLER N. Virtual Crowds: methods, simulation, and control. San Rafael: Morgan \& Claypool Publishers, 2008.

PEREIRA, L. A. Estudo do Tempo de Evacuação Total em Ambientes Gerais Via Autômatos Finitos. 2007. 63 f. Dissertação (Mestrado em Estatística) - Departamento de Estatística, Universidade Federal de Minas Gerais, Belo Horizonte, 2007.

ROJAS, R. Fuzzy Logic. In: Neural Networks: a systematic introduction. Berlim: Springer-Verlag, 1996. cap. 11 , p. 297-318.

SCHADSCHNEIDER, A. et al. Evacuation Dynamics: empirical results, modeling and applications. In: MEYERS, B. (Ed.). Encyclopedia of Complexity and System Science. Berlim: Springer, 2009. v. 5, p. 3142-3176.

SILVA, V.; COELHO FILHO, H. S. Índice de Segurança Contra Incêndio Para Edificações. Ambiente Construído, Porto Alegre, v. 7, n. 4, p. 103-121, out./dez. 2007.

SILVA FILHO, L. C. P. et al. (Coord.). Análise do Sinistro na Boate Kiss, em Santa Maria, RS. Porto Alegre: CREA-RS, 2013.

SIMÕES, M. G.; SHAW, I. S. Controle e Modelagem Fuzzy. 2. ed. São Paulo: Blucher, 2007. 
SOUZA, W. Reação ao Fogo dos Materiais: uma avaliação de saídas de emergência em edificações não industriais. Ouro Preto, 2007. 120 f.

Dissertação (Mestrado em Engenharia de Materiais) - Rede Temática em Engenharia de Materiais da Universidade Federal de Ouro Preto, Ouro Preto, 2007.

STAAL, M. A. Stress, Cognition and Human Performance: a literature review and conceptual framework. Moffet Field: Nasa, 2004.

STILL, G. K. Crowd Dynamics. Warwick, 2000. $280 \mathrm{f}$. Thesis (Doctor of Philosophy in Mathematics) - Department of Mathematics of University of Warwick, Warwick, 2000.

TAVARES, R. M.; GALEA, E. R. Evacuation Modeling Analysis Within the Operational Research Context: a combined approach for improving enclosure designs. Building and Environment, v. 44, n. 5, p. 1005-1016, may 2009.

THOMPSON, P.; MARCHANT, E. W. Computer Model of the Evacuation of Large Building Populations. Fire Safety Journal, v. 24, n. 2, p. 131-148, mar./apr. 1995a.
THOMPSON, P.; MARCHANT, E. W. Testing and Application of the Computer Model "SIMULEX". Fire Safety Journal, v. 24, n. 2, p. 149-166, mar/apr. 1995b.

VIDAL, M. C.; BONFATTI, R. J.; CARVÃO, J. M. Ação Ergonômica em Sistemas Complexos: proposta de um método de interação orientada em situação: a conversa-ação. Ação Ergonômica, v. 1, n. 3, p. 39-64, set. 2002.

VIDAL, M. C.; CARVALHO P. V. R. Ergonomia Cognitiva: raciocínio e decisão no trabalho. Rio de Janeiro: EVC, 2008.

VIEL, É. A Marcha Humana, a Corrida e o Salto: biomecânica, investigações, normas e disfunções. Barueri: Manole, 2001.

\section{Agradecimentos}

Os autores deste trabalho agradecem ao Cefet-MG, Fapemig, Capes e CNPq, pelo suporte material e financeiro obtidos.

\footnotetext{
Henrique Costa Braga

Pós-Graduação em Modelagem Matemática e Computacional | Centro Federal de Educação Tecnológica | Av. Amazonas, 7675, Nova Gameleira | Belo Horizonte - MG - Brasil | CEP 30510-000 | Tel.: (31) 3319-6807 | E-mail: bragaseg@yahoo.com.br

Gray Farias Moita

Pós-Graduação em Modelagem Matemática e Computacional | Centro Federal de Educação Tecnológica | E-mail: gray@dppg.cefetmg.br

Fausto Camargo

Pós-Graduação em Modelagem Matemática e Computacional | Centro Federal de Educação Tecnológica | E-mail: faustocjr@uol.com.br

Paulo Eduardo Maciel de Almeida

Pós-Graduação em Modelagem Matemática e Computacional | Centro Federal de Educação Tecnológica | E-mail: pema@lsi.cefetmg.br
}

\author{
Revista Ambiente Construído \\ Associação Nacional de Tecnologia do Ambiente Construído \\ Av. Osvaldo Aranha, $99-3^{\circ}$ andar, Centro \\ Porto Alegre - RS - Brasil \\ CEP 90035-190 \\ Telefone: +55 (51) 3308-4084 \\ Fax: +55 (51) 3308-4054 \\ www.seer.ufrgs.br/ambienteconstruido \\ E-mail: ambienteconstruido@ufrgs.br
}

